\title{
Desafios de mães de crianças com paralisia cerebral
}

\author{
Patrícia da Silva Bezerra* \\ Ruth Daisy Capistrano de Soura** \\ Fernando Augusto Ramos Pontes*** \\ Simone Souza da Costa Silva****
}

\begin{abstract}
Resumo
A paralisia cerebral (PC) é um conjunto de desordens motoras ocasionadas por uma lesão cerebral nos primeiros estágios de desenvolvimento. A presença de uma criança com PC na família ocasiona diversos desafios. O objetivo deste estudo foi descrever desafios de mães de crianças com PC. É uma pesquisa qualitativa e quantitativa dos dados obtidos durante uma intervenção que foi constituída de seis encontros, dela emergiram os dados qualitativos. Os dados quantitativos foram obtidos por meio da aplicação de um Inventário Sócio Demográfico. As mães são, em sua maioria, residentes de Belém, vivendo em união estável com seus parceiros e com escolaridade variando entre ensino fundamental incompleto e ensino médio completo. O estudo constatou alguns desafios vivenciados por essas mães, que foram organizados em categorias: Opinião das pessoas, Adaptação às atividades da vida diária, Dificuldades de acessibilidade e Inclusão. Foi observado com mais frequência o desafio referente a opinião das pessoas.
\end{abstract}

Palavras chave: Paralisia Cerebral - Mães - Desafios.

\section{Abstract}

Cerebral Palsy (PC) is a set of motor disorders caused by a brain injury in the early stages of development. The presence of a child with PC in the family poses several challenges. The objective of this study was to describe the challenges of mothers of children with PC. It is a qualitative and quantitative research of data obtained during an intervention that consisted of six meetings, from which the qualitative data emerged. The quantitative data were obtained through the application of a Socio-Demographic Inventory. Mothers are mostly residents of Belém, living in stable union with their partners and with schooling ranging from incomplete elementary school to full high school. The study found some challenges experienced by these mothers who were organized in categories, such as: "People's opinions", "Adaptation to activities of daily living", "Difficulties with accessibility" and "Inclusion". The challenge which was frequently observed by the mothers was: "People's opinions".

Keywords: Cerebral Palsy - Mothers - Challenges

* Graduanda do curso de Bacharelado em Serviço Social pela Universidade Federal do Pará.

** Pedagoga pela UES do Pará. Doutora e Mestre pela Universidade Federal do Pará.

***Psicólogo Mestre e Doutor pela UFPA. Pós-doc pela UNB e pela Technischen Universitat Dortmund - Alemanha. Professor associado IV da Universidade Federal do Pará.

****Psicóloga e Mestre pela UFPA. Doutora pela UNB e pela Technischen Universitat Dortmund - Alemanha. Diretora e Professora Adjunta do Núcleo de Teoria e Pesquisa do Comportamento da UFPA. 
PATRÍCIA DA SILVA BEZERRA et al.

\section{Introdução}

A Paralisia Cerebral (PC) pode ser definida como um grupo de desordens motoras ocasionadas por uma lesão cerebral nos primeiros estágios de desenvolvimento, que não são progressivas, porém, são mutáveis. De acordo com a localização da lesão, a paralisia cerebral pode causar déficits na postura, no tônus muscular e na execução de movimentos, impossibilitando-as a andar, falar ou escrever (Rosenbaum, Paneth, Leviton, Goldstein, Bax, Damiano, Dan \& Jacobsson, 2006).

A Paralisia Cerebral afeta, segundo o Ministério da Saúde, cerca de 5 a 7 crianças a cada 1000 no Brasil. As causas podem estar relacionadas a fatores que ocorreram antes, durante ou depois do nascimento da criança. Esta lesão compromete o desenvolvimento motor, sensorial e/ou cognitivo da criança. O nascimento de uma criança com paralisia cerebral demanda diversas adaptações da família. Os recursos disponíveis, as características familiares e as necessidades da criança são fatores que influenciam diretamente nessa adaptação (Jacques, 2003).

Azevedo, Spinazola, Cia e Mendesl (2013) realizaram um estudo que constatou que os cuidadores principais de crianças com deficiência são, em sua maioria, as mães. Essas por passarem a maior parte do tempo com a criança, acabam não podendo usufruir de um tempo para si. Nesse sentido, as mães aparecem como pessoas bastante sobrecarregadas, no entanto esta sobrecarga não influencia em sua dedicação aos cuidados com a criança. Batista e França (2007) realizaram um estudo sobre desafios e superação de famílias de pessoas com deficiência. Os autores constataram que a pessoa com deficiência, a família e a comunidade se influenciam mutuamente. Sugerem que o conhecimento construído sobre a pessoa com deficiência, sobre a família e sobre a comunidade em que ela está inserida fomenta a interação e oportunizam alternativas ligadas à inclusão. Uma sociedade bem-sucedida seria aquela que favorece a convivência e o respeito à diversidade.

Guerra, Dias, Filha, Andrade, Reichert e Araújo (2014) realizaram um estudo onde constataram que os desafios e dificuldades estão ligados a fatores como a intensa demanda de cuidados com a criança e ao enfrentamento de preconceitos na sociedade. Adicionalmente verificaram que apesar dos diversos momentos de dor e dificuldade descritos pelas mães de crianças com deficiência, estas aprendem a superar as diversas barreiras e preconceitos, tornando-se fortes e passando a acreditar na possibilidade de uma sociedade mais inclusiva e menos preconceituosa.
Falkenbach, Drexsler e Werler (2008) realizaram um estudo sobre sentimentos e experiência na relação entre a mãe e o filho com deficiência. O estudo constatou que existe uma intensa preocupação frente ao processo de inclusão social da criança. Apesar disso, torna-se evidente que após o nascimento de um filho com deficiência os pais reconsideram seus conceitos e passam a acreditar mais nas potencialidades de uma criança com deficiência.

Diante disso, fica evidente que famílias que passam a ter uma pessoa com deficiência em sua estrutura enfrentam diversos desafios e dificuldades, que vão desde o preconceito, a necessidade de superação, as adaptações em atividades diárias, dentre outras questões. Diante disso, o objetivo desse estudo foi descrever os desafios enfrentadas por mães de crianças com Paralisia Cerebral.

\section{Método}

O estudo desenvolveu-se a partir de uma intervenção realizada com 12 mães de crianças com paralisia cerebral atendidas pelo serviço de um hospital universitário da região metropolitana de Belém/PA. A intervenção teve por objetivo aliviar o nível de estresse parental e oferecer informações sobre a paralisia cerebral, cuidados com a criança, legislação, serviços, etc.

A participação das cuidadoras ocorreu mediante assinatura do Termo de Consentimento Livre e esclarecido em que foram apresentados os propósitos da pesquisa, conforme previsto na Resolução no. 510 de 17 de abril de 2016 do Conselho Nacional de Saúde/Ministério da Saúde, que dispõe sobre as normas de pesquisas envolvendo seres humanos. Garantindo, dessa maneira, às participantes, a confidencialidade das informações e o direito ao acesso dos resultados.

Foi utilizado um Inventário Sócio Demográfico (ISD) com o objetivo de fazer uma caracterização das participantes. Este é constituído por três sessões, a saber: Identificação dos sujeitos pertencentes ao grupo familiar; características socio econômicas e dados referentes à criança com paralisia cerebral. A coleta de dados com o ISD se deu nas dependências do hospital universitário, onde as participantes foram abordadas e convidadas à responder ao questionário. O processo de intervenção foi constituído de seis encontros, cada um deles tendo um tema específico. Todas as sessões de intervenção foram filmadas e posteriormente transcritas no Software Word, resultando em mais de dez horas de gravação e 98 páginas de transcrição. Os dados do Inventário Sócio Demográfico foram inseridos no Software SPSS (The Statistical Package for Social Science for Windows, versão 20.0) para 
melhor analise dos mesmos. Por questões éticas e para preservar a identidade dos participantes, nesse estudo, tanto as cuidadoras quanto os profissionais envolvidos na intervenção e as crianças receberam nomes fictícios.

\section{Resultados e discussão}

As principais informações sócio demográficas das participantes da intervenção foram reunidas com vistas a tornar conhecido o perfil da população participante da pesquisa.

Tabela 1: Caracterização das participantes

\begin{tabular}{|c|c|c|}
\hline \multicolumn{3}{|c|}{ Caracterização das participantes } \\
\hline \multirow[t]{3}{*}{ Idade } & Mínima & 22 \\
\hline & Média & 34,4 \\
\hline & Máxima & 55 \\
\hline \multirow[t]{2}{*}{ Moradia } & Belém (PA) & $83,3 \%(10)$ \\
\hline & Cidades vizinhas & $16,7 \%(2)$ \\
\hline \multirow[t]{4}{*}{ Estado Civil } & Solteiras & $16,6 \%(2)$ \\
\hline & União Estável & $58,3 \%(7)$ \\
\hline & Casadas & $8,3 \%(1)$ \\
\hline & Divorciadas & $8,3 \%(1)$ \\
\hline \multirow[t]{4}{*}{ Escolaridade } & Fundamental Inc. & $25 \%(3)$ \\
\hline & Fundamental Comp. & $16,6 \%(2)$ \\
\hline & Médio Inc. & $25 \%(3)$ \\
\hline & Médio Comp. & $33,3 \%(4)$ \\
\hline
\end{tabular}

\section{Desafios apresentados pelas mães durante a intervenção}

Durante o processo de intervenção foram discutidos diversos temas relacionados à paralisia cerebral, aos cuidados à criança, legislação, serviços, etc. A partir das falas das participantes foi possível identificar alguns desafios vivenciados por essas mães, que foram citados em cada um dos dias.

\section{Opinião das pessoas}

A partir da análise das falas das participantes foi identificado que no primeiro e no segundo dia da intervenção o desafio mais citado foi a opinião que as pessoas dispõem sobre elas enquanto mães e seus filhos. A categoria "Opinião das pessoas" foi frequente nos dois primeiros dias e consiste não apenas na percepção das pessoas sobre a família de uma criança com PC, mas também a importância atribuída pelas mães à avaliação que a comunidade faz de seus comportamentos. A opinião das pessoas seja ela positiva ou negativa, de encorajamento ou desencorajamento, gerou sentimentos e reações particulares nessas mães.

É difícil para a sociedade aceitar e acolher aquilo que se distancia do padrão, como é o caso das pessoas com deficiência. $\mathrm{O}$ processo de exclusão e preconceito existe desde a antiguidade, onde determinadas comunidades que se apresentavam como grupos fortes não aceitavam os ditos fraco ou inaptos, como as pessoas com doenças crônicas ou com uma deficiência (Santos \& Paulino, 2008). Observa-se que apesar dos avanços e transformações que a sociedade vem vivenciando ao longo do tempo, a questão do preconceito com as pessoas com deficiência ainda é

Tabela 2: Desafios relatados pelas participantes durante a intervenção.

\begin{tabular}{l|c|c}
\hline & Tema do dia & Desafios \\
\hline Primeiro dia & $\begin{array}{c}\text { Apresentação do grupo e } \\
\text { levantamento das principais } \\
\text { necessidades e dificuldades no } \\
\text { cuidado ao filho com paralisia } \\
\text { cerebral }\end{array}$ & Opinião das pessoas \\
\hline Segundo dia & O que é Paralisia Cerebral? & Opinião das pessoas \\
\hline Terceiro dia & Atividades de cuidados diários \\
com o filho & Adaptação às atividades da vida diária \\
\hline Quarto dia & Legislação e Serviços & Dificuldades de acessibilidade \\
\hline Quinto dia & Estresse & Dificuldades de acessibilidade \\
\hline Sexto dia & Avaliação da intervenção & Inclusão
\end{tabular}


bastante recorrente, como pode ser observado nos relatos de algumas participantes desta pesquisa.

No caso das crianças com paralisia cerebral, as mães sentem bastante esse preconceito direcionado ao filho e também a elas, por serem mães dessas crianças e muitas vezes serem vistas como culpadas. Por isso, lidar com essas opiniões, que majoritariamente são negativas e de desencorajamento, é um desafio enfrentado por elas.

Os diversos tipos de opinião e até mesmo julgamento direcionado a essas mães gerou sentimentos e reações diferentes ou em comum em cada uma. Há aquelas que ao ouvir de alguém que devem desistir de buscar tratamento reagem de forma contrária, buscando com mais dedicação os tratamentos que as pessoas conjecturam desnecessários. Algumas mães sentem-se tristes com o fato de muitas pessoas pensarem que a deficiência foi ocasionada por uma tentativa de aborto, e atribuem isso à falta de informação. Nesses casos, as mães relataram que travavam discussões com intuito de alterar as percepções equivocadas das pessoas.

"É, porque a gente que tem essas crianças com paralisia cerebral a opinião contrária não é aceita, eu pelo menos não aceito. Se ela chegar assim 'ah, ele não tem movimento tu tá correndo atrás de que? De ele ganhar o movimento?' Eu digo 'não, eu vou correr sim porque eu tenho certeza que ele vai ganhar esse movimento', agora se eu não correr, se eu ficar acomodada..." (Roberta)

Verificou-se que as mães tentam ignorar as opiniões negativas e desencorajadoras, e mesmo que as vezes se sintam abatidas por estas, tentam superar o abatimento e agir de forma contrária do previsto pelas pessoas. Isso torna-se ainda mais relevante ao pensar que a comunidade é a primeira extensão da família, é onde o sujeito vive, sendo um grupo repleto de particularidades (Batista \& França, 2007).

Diante disso, os mesmos autores apontam que a família é sempre afetada por determinações sociais e reage a essas determinações, influenciando direta ou indiretamente o desenvolvimento (Batista \& França, 2007). Isso significa, por exemplo, que a opinião das pessoas tem significativas influências (positivas e/ou negativas) na vida dessas mães. O que pode ser constatado no presente estudo, onde há grande enfrentamento das mães diante das críticas postas por diversas pessoas.

"A mesma coisa surgiu também (...) aí dizem que eu tomei remédio e que a minha filha nasceu assim com problema, só que eu sofro e o pai dela sofre porque nós dois sabemos que não, eu e ele e a minha família que convive comigo diretamente, entendeu?! E a gente sofre com isso, é muito assim o pessoal na rua vê eu carregando um bebezão no colo 'Isso foi remédio que ela tomou, ela tentou abortar a menina'." (Joana)

Jorge, Eusébio e Lopes (2014), em um estudo sobre resiliência em famílias de pessoas com deficiência, afirmam que a forma como uma família enfrenta determinadas situações adversas os influencia nas adaptações imediatas e em longo prazo. No caso das participantes desta pesquisa, as atitudes de enfrentamento e superação das críticas negativas expostas a elas podem ser evidenciados como comportamentos de famílias resilientes. Para Walsh (2005), resiliência em famílias refere-se não apenas aos processos de adaptação, mas também às transformações positivas que decorrem do enfrentamento de determinadas situações que podem ser estressantes.

Diante disso, pode-se constatar que as mães participantes dessa pesquisa apresentaram muitas características de enfrentamento e superação dos desafios. As opiniões negativas e de desencorajamento, apesar de gerar tristeza não fez com que elas desistissem de buscar tratamento para a criança, por exemplo, mas ocasionou uma busca ainda mais intensa em prol do melhor desenvolvimento de seus filhos.

\section{Adaptação às atividades da vida diária}

A segunda categoria mais relatada pelas cuidadoras foi denominada de "Adaptação às atividades da vida diária", que se refere a um conjunto de desafios encontrados por essas mães no cuidado a criança com PC.

As crianças com Paralisia Cerebral necessitam de cuidados específicos, sendo fundamental a adaptação da rotina dessas mães. Elas relataram algumas estratégias e ideias que utilizam para fazer adaptações que vão desde o treino ao toilet, o vestir a roupa, escovar os dentes, dentre outras.

"É que nem o negócio de eu levar ela no banheiro pra fazer as necessidades dela, to ensinando, que ela só usa frauda. Quer saber de uma coisa, vou colocar ela pra fazer o cocozinho dela lá no vaso, comprei um negócio de ursinho né, pra ela ficar sentada, aí ela olha, eu falo 'tu não quer sentar' aí ela (levanta aos mãos se afastando) fica assim, que não. "Então eu vou sentar aí depois tu vai sentar", aí eu sento e ponho ela na minha perna sentada, aí eu saio devagarzinho, e deixo ela, aí ela, ela fica, mas ela não faz. (...) Não eu falo pra ela, se ela aprendeu a vestir a calcinha dela, aprendeu a calçar a sandália dela, 
sabe quando ela tá com fome ela vai na geladeira, ela come, ela vai ter que aprender a fazer coco la no vaso" (Joana, mãe da Beatriz)

Nessa fala, observou-se a dificuldade da criança em se adaptar à uma atividade do dia a dia. A mãe utiliza-se de estratégias para que a criança possa se habituar à essa prática, porém, ainda assim as dificuldades permanecem.

É evidente que o nascimento de uma criança traz mudanças significativas para o ambiente familiar. No entanto estas mudanças são maiores em se tratando do nascimento de uma criança com deficiência.

Hollerweger e Catarina (2014) apontam que o nascimento de uma criança com deficiência é uma situação inesperada e confrontadora para os pais. Há uma quebra de expectativas em relação à criança e seu futuro, assim como a experiência de parentalidade passa por um processo de ressignificação. Hollerweger e Catarina (2014) e Dantas, Collet, Moura e Torquato (2010) afirmam que a existência de uma criança com Paralisia Cerebral ocasiona intensas mudanças na realidade familiar. A compreensão de que as características da deficiência persistirão proporciona esforços ainda mais intensos que permitirão a adaptação familiar a nova rotina.

"Eu também tenho esse problema porque a minha casa é muito pequena, é um ovo, e a Raquel já tá grande, ela tá com 8 anos, ela é muito comprida, aí eu tenho dificuldade pra dar banho porque não tem nem como colocar a cadeira que eu ganhei de banho no banheiro, não entra. Então eu tenho que tomar banho junto com ela toda vez, então na média eu tomo quatro, cinco, seis banhos por dia, conforme for já tomo junto com ela e depois tem os meus banhos só". (Eduarda, mãe da Karina)

Nessa fala a mãe relata a sua dificuldade na hora de dar banho na filha e as estratégias que utiliza para realizar essa atividade. Os diversos relatos das participantes demonstraram as diferentes formas utilizadas por elas para adaptar a realidade de forma simples. A literatura aponta que, em sua dinâmica cotidiana, famílias de crianças com deficiência tendem a buscar formas para se readaptar e enfrentar essa nova situação, que é ter um filho com PC (Dantas et al., 2010).

Oliveira, Silva, Oliveira e Gomes (2008) em seu estudo sobre qualidade de vida do cuidador de pessoas com paralisia cerebral constataram que mesmo diante das dificuldades as cuidadoras encontram formas de enfrentar a condição do cuidar. Foi constatado que mesmo diante de muitas renuncias que precisam ser feitas devido ao cuidado com a criança, as mães sentem-se realizada por atenderem às demandas de seu filho.

\section{Dificuldades de acessibilidade}

O terceiro desafio apresentado pelas mães apareceu com frequência nos dias 4 e 5 da intervenção. Esse desafio foi nomeado de "Dificuldades de acessibilidade". Sobre esta categoria, identificou-se falas onde as cuidadoras relatam falta de acessibilidade em locais públicos, em transportes públicos e até mesmo em casa. A falta de acessibilidade, além disso, pode agravar ainda mais a situação quando não ocorre, por exemplo, um bom diálogo com um motorista de um ônibus, como foi relatado por uma mãe. A fala a seguir expressa melhor esta questão:

“(...) eu andava muito com a Bianca quando a gente tinha um carro (...) eu colocava a cadeira da Bianca atrás e ia, agora se eu for depender de ônibus que eu fiquei esses dois anos sem carro, eu prefiro nem sair porque nem todos os ônibus têm pra colocar a cadeira, tu passa meia hora, uma hora esperando na parada um ônibus que passa isso quando funciona o aparelho né, que às vezes não funciona aí tem que esperar um que funcione, aí o motorista vem com aquela cara feiosa pra ti pra poder descer aquilo" (Juliana).

A partir desses relatos, pode-se observar que existem mães que deixam de sair de casa priorizando apenas as situações imprescindíveis como o tratamento da criança, devido à falta de acessibilidade em transportes públicos. A falta de acessibilidade é um problema grave nas grandes cidades seja devido as barreiras físicas, pois muitos transportes não são adaptados para pessoas com deficiência, seja por barreiras atitudinais já que é fácil encontrar pessoas que não querem sair da sua zona de conforto para incluir uma pessoa com deficiência.

Nonato (2011) em sua pesquisa sobre acessibilidade arquitetônica para pessoas com deficiência, escreve que "as cidades brasileiras, em sua maioria, não estão preparadas para possibilitar que as pessoas com deficiência possam acessar, permanecer e utilizar os múltiplos espaços, das edificações, dos mobiliários urbanos, dos elementos da urbanização, dos equipamentos urbanos e dos serviços de uso público e coletivo, com autonomia, segurança, independência e comodidade".

Além dessas, existem também as barreiras atitudinais, que surgem nas expressões de discriminação e indiferença vivenciados pelas mães. Um exemplo são as situações vivenciadas em transportes públicos, quando o motorista se recusa a levar a mãe e a criança com de- 
ficiência, demonstrando preconceito e falta de preparo profissional para lidar com as diferenças.

Essa falta de acessibilidade influencia diretamente nas dificuldades que as mães têm de sair com a criança, seja para algum tratamento médico, seja para qualquer outra atividade. Alguns relatos mostram que elas chegam atrasadas em muitos lugares, e até mesmo em consultas ou terapias do filho por ter o transporte público como único meio de se locomover, sendo a maioria destes sem a devida adaptação para atender pessoas com deficiência.

Em outros casos, as mães revelam que passam situações difíceis em ônibus lotados onde as pessoas não oferecem ajuda, demonstrando que a questão da falta de acessibilidade, muitas vezes, refere-se não apenas à estrutura do local ou transporte, mas também a aspectos comportamentais. As falas revelam que são várias as vezes que o motorista age de forma inadequada, assim como é frequente as pessoas que fazem uso dos espaços agirem de modo indiferente.

Esse tipo de dificuldade pode ser caracterizado como barreiras atitudinais, onde as relações humanas centram-se nas restrições dos indivíduos, e não em suas habilidades (Gotti, 2006). As barreiras atitudinais são expressas por meio de preconceitos, discriminação, estigmatização e diversas outras formas, fortalecendo assim o processo de exclusão social das pessoas com deficiência (Guedes, 2007). A fala a seguir expressa melhor essa questão:

"É, porque assim, o meu pai trabalha então o carro não é dele, entendeu?! Então, o Matheus tem fisioterapia toda quarta feira, e dia de quarta-feira de manhã ele não tem assim, só dá pra ele pelo período da tarde, entendeu?! Então, o que eu penso assim, poxa, até eu pegar o ônibus com ele, eu vou de duas conduções, eu desço na frente do Santa Rosa e fico esperando o UFPA Pedreira, e quando vem, vem muito lotado, então quando eu subo no ônibus as pessoas não têm aquela entendeu?! De levantar pra mim sentar com ele, e as vezes ele tá assim muito rígido sabe, ele fica todo duro sabe, e eu não tenho assim, ele tem uma força que só ele e Deus sabe, porque eu não sei de onde vem, e as pessoas não tem aquela noção sabe, as vezes eu vou ali até próximo à Unimed, o Banco do Brasil, com ele em pé, no colo, entendeu?!” (Bruna)

Ponte e Silva (2015) realizaram um estudo sobre a percepção de pessoas com deficiência acerca das barreiras atitudinais. $\mathrm{O}$ estudo constatou que as barreiras atitudinais são praticadas no dia a dia e em atividades simples. Os obstáculos mais referenciados no estudo mencionam- os obstáculos existentes nos transportes públicos, ao desrespeito no trânsito e à falta de informações sobre como lidar com uma pessoa com deficiência. A fala a seguir expressa melhor essa questão:

Pode-se constatar, então, que os desafios relacionados à falta de acessibilidade em locais e transportes públicos é um problema a ser enfrentado tanto no âmbito governamental, ao se exigir a adaptação dos espaços para pessoas com deficiência, como também em termos comportamentais, a partir do processo de desconstrução de preconceitos existentes nas pessoas desde a antiguidade.

\section{Inclusão}

O último e importante desafio apresentado nas falas das mães é o da "Inclusão". Essa questão gira em torno, principalmente, do receio que muitas delas demonstraram sobre inserir o filho na escola. Existem algumas que admitem a importância de sair com o filho para diversos lugares, pois acreditam que a inclusão é de significativa importância para seu desenvolvimento, mas esbarram na questão da permissão de deixar o filho na escola.

"Enfrentar. Porque se ficar em casa, vai ser constrangedor pra gente, e pra eles muito mais. Porque a gente tá tirando eles de se incluir, de ver o outro lado da vida, né. E pra gente também porque a gente vai ficar tipo achando que tá isolando o próprio filho da gente. (...) Porque assim a gente, né, no meu caso, eu demorei mais pra colocar o Marcelo na escola por medo. Ah, as pessoas não vão gostar do Marcelo, eles vão beliscar o Marcelo, o maior medo é beliscar, bater". (Rosana)

É importante salientar o progresso de algumas mães em relação à permitir que o filho frequente a escola. Esse relato demonstra uma quebra de paradigmas que foi um grande desafio para a mãe que avaliou positivamente sua decisão de inserir seu filho na escola, pois admite as melhoras no desenvolvimento da criança desde então.

Faz-se significativo considerar que existem, atualmente, muitos obstáculos na área educacional para crianças com deficiência, e essas mães são cientes dessa realidade. Alciate (2011) constata que muitos professores do ensino regular não se sentem qualificados para atender as diferenças em sala de aula. Segundo a autora, a maior barreira apontada pelos professores é o fato de não terem sido preparados em termos pedagógicos e psicológicos para trabalhar com crianças com deficiência.

"Achei interessante na escola. A Clara também ela se arruma toda, né, pega a mochila dela, vai pra escola, e 
quando ela chega lá, todos os coleguinhas ficam tudo esperando ela, é engraçado, eles ajudam ela, quando ela cai, eles levantam ela, eles ficam preocupados com ela. Quando ela calça uma sandália assim, e sai do pé dela, eles põem no pé dela, eles demoram né, mas põe... (...) $\mathrm{E}$ sobre as fantasias também, tudo que tem na escola ela é a primeira, ela sempre participa de tudo, tudo, tudo, tudo. Eu me lembrei das fantasias dela" (Rosilene)

Os relatos mostram como algumas mães têm receio de inserir a criança na escola devido às suas limitações, por não saber se este será "maltratado" ou "bem tratado", como os professores vão reagir, etc. Isto pode estar atrelado às questões anteriormente expostas e debatidas, como a opinião das pessoas pois, como já fora exposto, estas opiniões, majoritariamente, são opiniões negativas e de desencorajamento.

Além disso, pode-se inferir, também, que o receio que as mães têm de inserir seus filhos na escola pode estar atrelado à essas opiniões negativas que elas recebem, de uma sociedade que culpabiliza principalmente as mães pela condição de deficiência da criança e, ainda, que não acredita num desenvolvimento de habilidades na criança com paralisia cerebral. Pode-se, ainda, somar a isto situações de falta de acessibilidade estrutural e atitudinal, principalmente esta última, levando em consideração que pode desencadear atitudes preconceituosas e discriminatórias (Guedes, 2007).

Isso tudo corrobora com o fato de muitas mães vivenciarem situações de discriminação e preconceito diariamente com as crianças. Devido a essas vivencias, acreditam que os filhos passarão por situações semelhantes na escola. Para essas mães, além da hipótese de os colegas de classe agirem com preconceito, compreendem que muitos professores não são capacitados para lidar com uma criança com deficiência, e que não compreenderão suas necessidades.

\section{Considerações finais}

Mães de crianças com Paralisia Cerebral encontram diversos desafios ao longo do desenvolvimento do filho. A compreensão sobre esses desafios permite aos profissionais de saúde obter subsídios para a criação e implantação de ações que atuem nessas áreas. Este conhecimento também auxilia as famílias de crianças com deficiência, pois proporcionam o conhecimento acerca de direitos, limitações, possibilidades, etc. de uma pessoa com deficiência. Os dados revelaram o quanto a vida dessas mães é, diariamente, marcada por desafios.

No que se refere às limitações deste estudo destaca-se a escassez de literatura sobre o tema Diante disso, sugere-se que futuros estudos se proponham a investigar os desafios que mães de pessoas com diferentes deficiências enfrentam no seu cotidiano.

\section{Referências}

Azevedo, T. L., Szinazola, C. C., \& Mendes, E. G. (2013) Impactos de um programa de intervenção para pais de crianças com deficiência ou autismo: avaliação das variáveis familiares. In VIII Encontro da associação brasileira de pesquisadores em educação especial (pp. 2231-2244). Londrina, PR.

Alciate, Â. C. (2011) Alunos deficientes em escolas regulares: Inclusão ou exclusão? Monografia (Especialização). Universidade Federal de Brasília, UnB, Distrito Federal, DF.

Batista, S. M., \& França, R. M. (2007, janeiro-junho) Famílias de pessoas com deficiência: desafios e superação 3(10), 117-121.

Dantas, M. S. A., Collet, N., Moura, F. M., \& Torquato, I. M. B. (2010) Impacto do diagnóstico de paralisia cerebral para a família. 19(2), 229-237. doi: http:// dx.doi.org/10.1590/S0104-07072010000200003

Falkenbach, A. P., Drexsler, G., \& Werler, V. (2008) A relação mãe/ criança com deficiência: sentimentos e experiências 13(2), 2065-2073. doi: http://dx.doi. org/10.1590/S1413-81232008000900011

Gotti, M. O; (2006) Educação Inclusiva: Avanços da educação de alunos surdos. Revista de Educação Especial

Guedes, L. C. (2007) Barreiras atitudinais nas instituições de ensino superior: questão de educação e empregabilidade. Tese (Doutorado). Universidade Federal do Pernambuco, UFPE, Recife, PE.

Guerra, C. S., Dias, M. D., Filha, M. O. F., Andrade, F. B., Reichert, A. P. S., \& Araújo, V. S. (2015, abril-junho) Do sonho a realidade: vivência de mães de filhos com deficiência 24(2), 459-466. Disponível em: http://pepsic.bvsalud.org/ scielo.php?script $=$ sci_arttext\&pid=S1677-29702015000200009

Hollerweger, S., \& Catarina, M. B. S. (2014) A importância da família na aprendizagem da criança especial. 9(19), 1-12. Disponível em: http://www.ideau.com. $\mathrm{br} /$ getulio/restrito/upload/revistasartigos/9_1.pdf

Jacques R. (2003) Family issues. [serial on line] Disponível em: http://www. intellectualdisability.info/families/ p_family_rj.html

Jorge, A. M., Eusébio, S. A. M. P., \& Lopes, F. M. T. (2014) Resiliência das famílias com filhos deficientes. International Journal Of Developmental and Educational Psychology: INFAD. Revista de Psicologia, 1 (1), 170-177.

Nonato, D. N. (2011) Acessibilidade arquitetônica como direito humano das pessoas com deficiência. 2(2), 138-164. Disponível em: http://www.cesrei.com.br/ojs/ index.php/orbis/article/viewFile/63/63

Oliveira, M. F., Silva, L. M., Oliveira, F. T., \& Gomes, T. T. (2008) A qualidade de vida de cuidadores de pacientes com paralisia cerebral. 21(4), 275-280. Disponível em: http://132.248.9.34/hevila/Revistabrasileraempromocaodasaude/2008/vol21/no4/7.pdf

Ponte, A. S., \& Silva, L. C. (2015) A acessibilidade atitudinal e a percep̧̧ão das pessoas com e sem deficiência. 23(2), 261-271.

Rosenbaum, P., Paneth, N., Leviton, A., Goldstein, M., Bax, M., Damiano, D., Dan, B., \& Jacobsson, B. (2006, Abril) A report: the definition and classification of cerebral palsy 49(109), 8-14. doi: http://dx.doi. org/10.1111/j.1469-8749.2007.tb12610.x

Santos, M. P., \& Paulino, M. M. (Orgs.) (2008) Dimensões e diálogos de exclusão: um caminho para inclusão. (2 edição), São Paulo, SP: Cortez.

Walsh, F. (2005) Fortalecendo a resiliência familiar. São Paulo, SP. Roca.

Submetido em: 28-8-2017

Aceito em: 11-12-2018 